
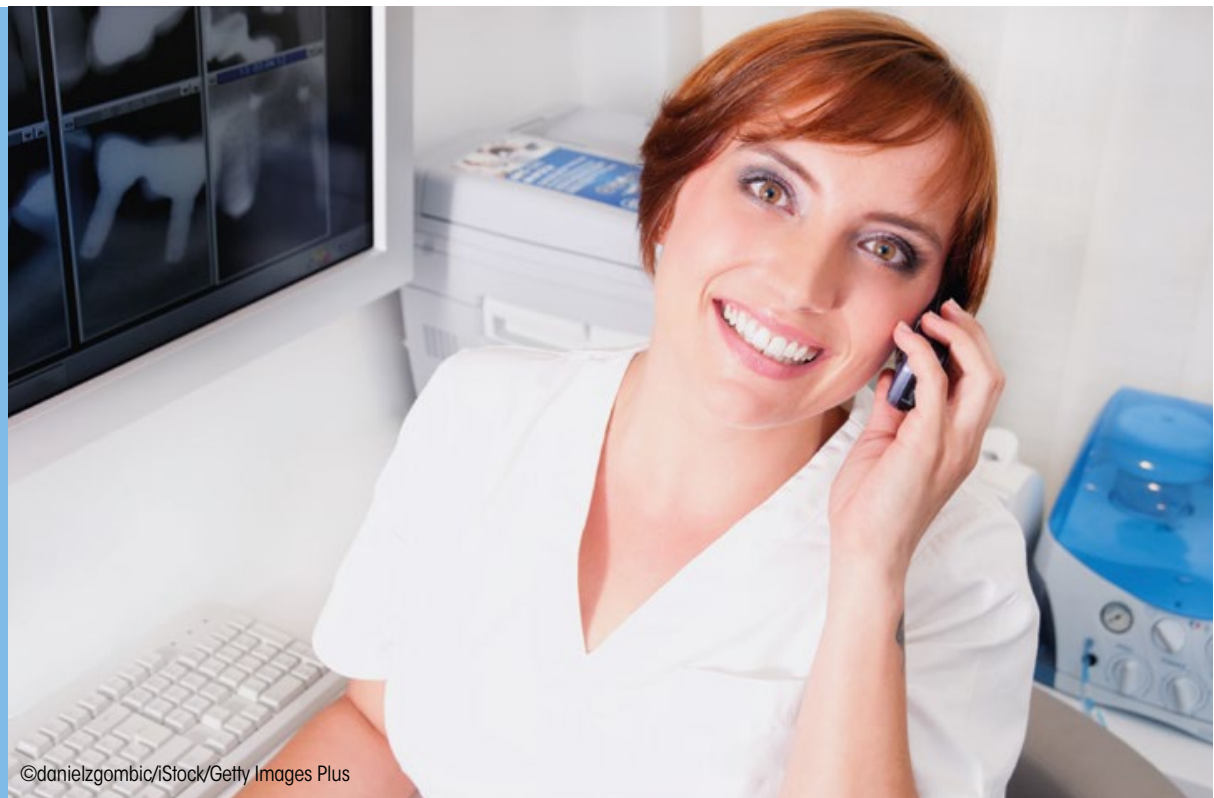

C)danielzgombic/iStock/Getty Images Plus

\title{
SCAMMERS EXPLOITING ORAL HEALTH FOUNDATION HELPLINE
}

The dental helpline run by the Oral Health Foundation is being exploited by scammers who have created premium line numbers purporting to be run by the foundation but which take money from unsuspecting callers.

The Foundation is alerting the public and the profession to the scam and highlighting that the only number for the helpline is a local-rate telephone num- ber: 01788539780 . The service is run by dentally qualified personnel, mostly dental nurses, and is free.

Dr Nigel Carter OBE, chief executive of the foundation, advised anybody wanting to contact the helpline to check the authenticity of the telephone number first. The helpline can be reached by email: helpline@dentalhealth.org or via the website: www.dentalhealth.org/dentalhelpline.

SUGAR CUBES GO AWAY, DON'T COME ' BACK ANOTHER DAY!

Primary school children will be taught how to count sugar cubes as part of the government's anti-obesity push. English and maths lessons will include anti-sugar messages in an attempt to improve children's diets. Children will use their times tables to work out how much sugar is in a bowl of cereal or a can of fizzy drink and will then see if it is more than the recommended daily allowance (RDA) in new worksheets provided by Public Health England. They will also be asked to find 'swaps' for healthier food and drink items.

In English classes, children will be asked to draw a comic saying that people should swap out sugar-laden foods for lighter alternatives. Other activities include designing a 'sugar swap' poster or writing a letter persuading people to consume less sugar. As well as the worksheets PHE I is offering slideshows for teachers to use

in class with one of the presentations for English lessons containing an anti-sugar song: 'Sugar cubes, go away, don't come back another day, you're not good for our teeth, sugar, go away'. In the background information provided for teachers, PHE warn that one child has a rotten tooth removed every ten minutes.

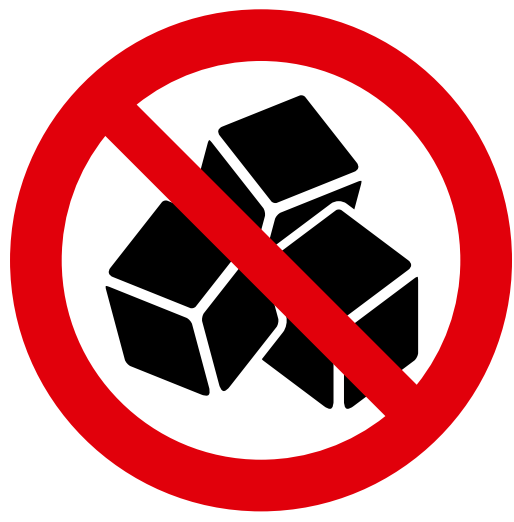

Gam disease may canse premature laboarr

Pregnant women with plaque are more likely to give birth before 37 weeks, research suggests. A study of dozens of new mothers found 45 per cent of those whose waters broke early had swollen, sore or infected gums. In comparison, only 29 per cent of the women who didn't give birth prematurely had signs of gum disease. Bacteria in plaque are thought to travel to the placenta via the bloodstream, causing it to became inflamed. This may disrupt the amniotic sac that surrounds the foetus, leading it to rupture too soon, scientists believe. The research was carried out by University Hospital Hradec Králové, Czech Republic, and led by Dr Vladimíra Radochová, from the department of dentistry and published in the Journal of Clinical Periodontology. Dr Nigel Carter, chief executive of the Oral Health Foundation, believes the study highlights the importance of looking after our teeth during every stage of our lives.

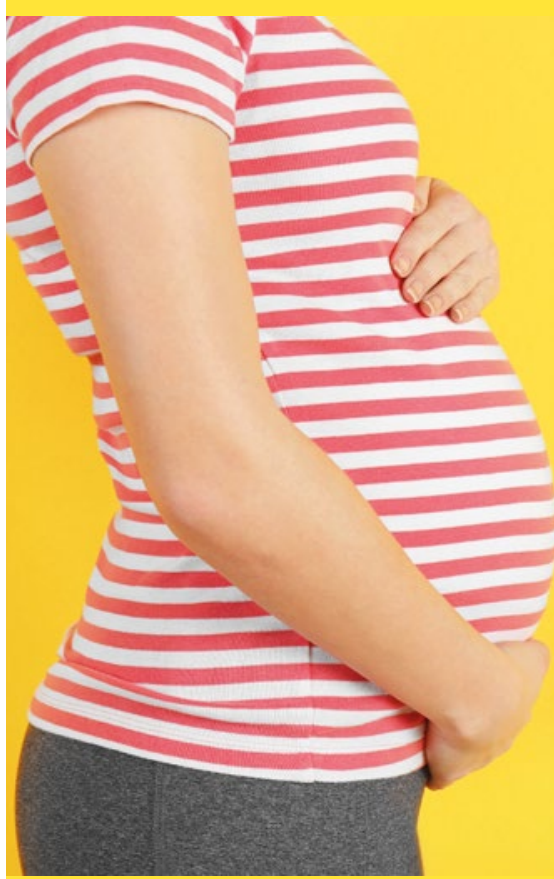

